\title{
The Myoepithelial Cell Layer May Serve As a Potential Trigger Factor for Difierent Outcomes of Stage-Matched Invasive Lobular and Ductal Breast Cancers
}

\author{
Yi-Hsuan Hsiao ${ }^{1,2}$, Horng-Der Tsai², Ming-Chih Chou $^{3 凶}{ }^{凶}$, Yan-gao Man ${ }^{4}$ \\ 1. Institute of Medicine, Chung Shan Medical University, Taichung, Taiwan \\ 2. Department of Obstetrics and Gynecology, Changhua Christian Hospital, Changhua, Taiwan \\ 3. Department of Surgery, Chung Shan Medical University, Taichung, Taiwan \\ 4. Armed Forces Institute of Pathology and American Registry of Pathology, Washington DC, USA
}

Corresponding author: Ming-Chih Chou, MD., PhD., Member, Board of Trustees, Professor, Department of Surgery, Chung Shan Medical University, Taichung, Taiwan. Tel: 886-4-24730022; Fax: 886-4-24723229; E-mail: graduate@csmu.edu.tw. Or Yan-gao Man, MD., PhD., Director of Gynecologic and Breast Research Laboratory, Department of Gynecologic and Breast Pathology, Armed Forces Institute of Pathology and American Registry of Pathology. Tel: 202-782-1612; Fax: 202-782-3939; E-mail: man@afip.osd.mil

Received: 2010.11.16; Accepted: 2011.02.01; Published: 2011.02.04

\begin{abstract}
Invasive lobular cancer (ILC) tends to be significantly larger in size with significantly more positive lymph nodes, whereas ILC has a significantly more favorable outcome, compared to stage-matched invasive ductal carcinoma (IDC). The mechanism accounting for such differences remains elusive. Based on morphological, immunohistochemical, and molecular studies of over I,000 cases of human breast cancers, we hypothesize that the differences may result from the structural and/or functional differences of their surrounding myoepithelial cell layers, which dictate lobular and ductal tumor cells to follow different pathways of invasion or metastasis. The background, rationale, supportive data, and implications of our hypothesis are presented and discussed.
\end{abstract}

Key words: Invasive lobular cancer, invasive ductal carcinoma, human breast cancers, myoepithelial cell layers

\section{Introduction}

It has been well documented and generally accepted that ILC tend to be significantly larger in size with a significantly higher rate of positive lymph nodes than its stage-matched ductal counterpart [1-3]. Although large tumor size and positive lymph node are two well-recognized risk factors for worse prognosis, patients with ILC have a substantially more favorable clinical outcome compared to patients with IDC [1-5]. These contradictory impacts have been largely attributed to the unique biological features of ILC, including the lack of E-cadherin expression, higher expression of ER and PR, lower expression of

HER-2, p53, and EGFR, and lower S-phase fraction [6-9]. The trigger factor for the significant differences in biological behavior and clinical outcomes between ILC and IDC, however, have not been identified

Based on our previous morphological, immunohistochemical, and molecular studies of over 1,000 cases of human breast cancers, we speculate that the substantial difference in clinical outcomes between ILC and IDC may results from the structural and functional differences of their surrounding myoepithelial cell layers, which control the genetic property and biological behavior of the pre-invasive lesions 
and dictate lobular and ductal tumors to follow different pathways for invasion and/or metastasis. Our speculation is consistent with a number of experimental findings and clinical reports.

\section{Structural differences in the myoepithelial cell layer between the lobular and ductal systems}

The epithelial cells of normal lobular and ductal systems are surrounded by the basement membrane and a layer of myoepithelial cells. The basement membrane is structurally similar in both, but the myoepithelial cell layer in the ductal system generally forms a ring-like structure completely surrounding all epithelial cells. In contrast, the myoepithelial cell layer in the lobular system is often discontinuous (defined as the lack of direct physical contact among adjacent myoepithelial cells or the presence of small gaps, generally smaller than the size of one myoepithelial cell) in some $(<20 \%)$ lobular clusters [10-12] (Fig 1).
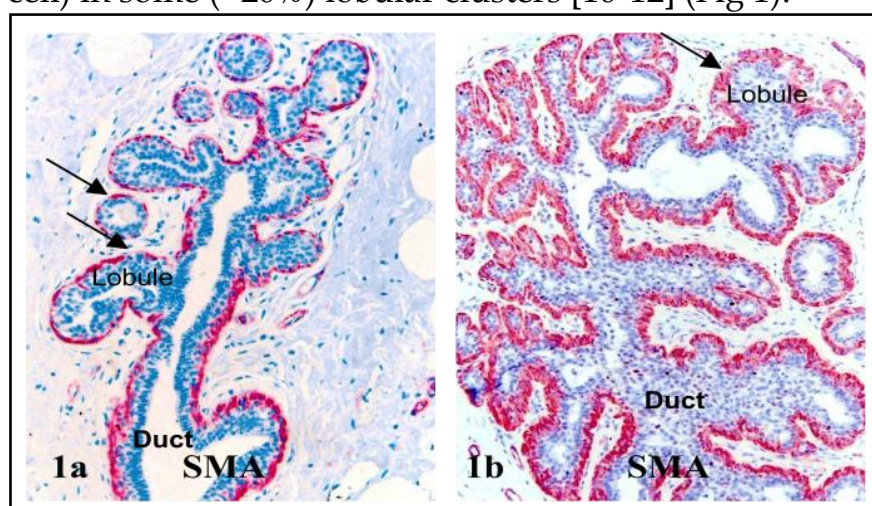

\section{Functional differences in the myoepithelial cell layer between the lobular and ductal systems}

The myoepithelial cell layer is the sole source of a number of tumor suppressors, including maspin, p63, and Wilms' tumor 1 (WT-1), which display significant inhibition on proliferation and invasion of associated tumor cells [13-18]. In the normal ductal system, tumor suppressors are consistently expressed in all or nearly all morphologically identifiable myoepithelial cells [15-17]. In contrast, a subset of morphologically distinct myoepithelial cells in the lobular system are often devoid of expression of tumor suppressors $[19,20]$ (Fig 2). In some cases, the lack of tumor suppressor p63 expression in myoepithelial cells was correlated with cytoplasmic p63 expression in the associated epithelial cells, which show increased aggressiveness and invasiveness [17, 20] (Fig 2c-2d).

Fig I. Structural variations in myoepithelial cell layer between the lobular and ductal systems. Normal human breast tissue sections were immunostained with a myoepithelial cell marker, smooth muscle actin (SMA; red) and a basement membrane marker, collagen IV (brown). Thick arrows identify the basement membrane. Thin arrows identify myoepithelial cell layers. Note that the myoepithelial cell layer is more distinct in the duct than in the lobular system. I50X.

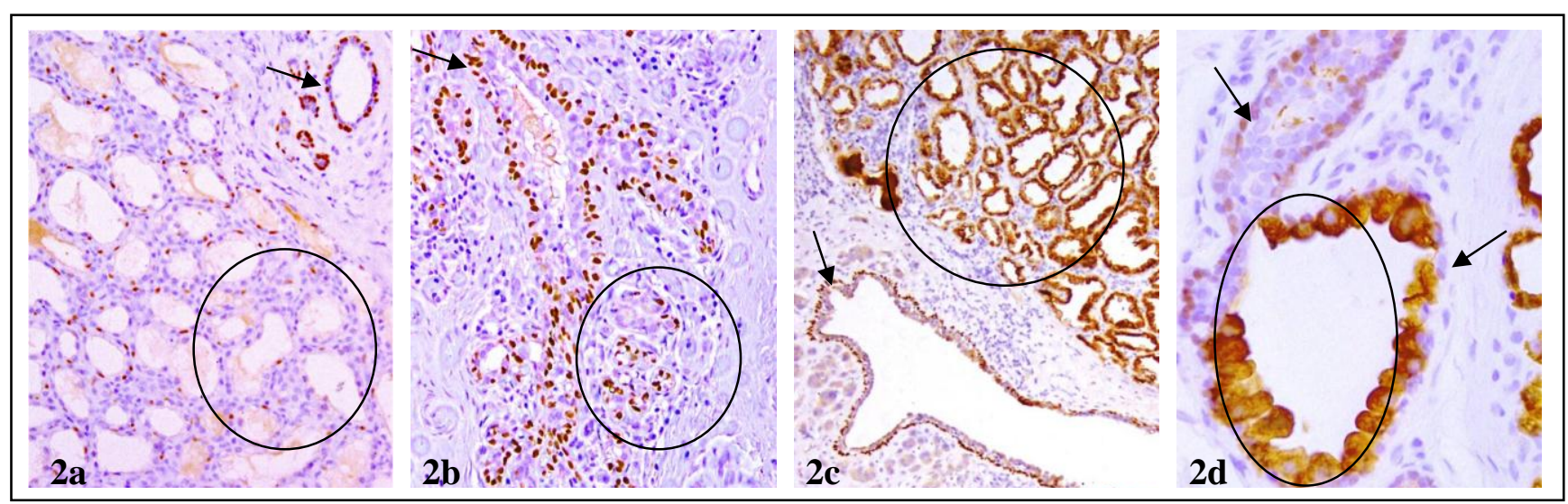

Fig 2. Differential expression of tumor suppressors in myoepithelial cell layers of the lobular and ductal systems. Human breast tissue sections were immunostained for tumor suppressor p63. Circles identify lobules with no or cytoplasmic p63 expression. Arrows in a-c identify normal p63 expression in ducts. Arrow in D shows myoepithelial cell lacking p63. 200X. 
In addition, the myoepithelial cell layer in the entire lobule of some cases show signs of degenerative changes, including a significantly lower frequency of proliferation and expression of tumor suppressors and other phenotypic markers, whereas a significantly higher frequency of apoptosis, focal disruptions and leukocyte infiltration [21-24]. Pre-invasive breast tumors with aberrant expression of tumor suppressors in the myoepithelial cell layers had a significantly higher proliferation, genetic and biochemical abnormalities than their morphologically similar counterparts with normal expression of these tumor suppressors [25-30] (Fig 3).

\section{Correlation between the status of myoepi- thelail cell layers and biological presentations of tumor cells}

The status of the myoepithelial cell layer appears to correlate with the biological presentation of associated epithelial cells. A number of cell surface adhesion molecules, including E-cadherin, are strongly expressed in nearly all ductal cells and their malignant derivatives, but are absent in their lobular counterparts [31,32] (Fig 4).

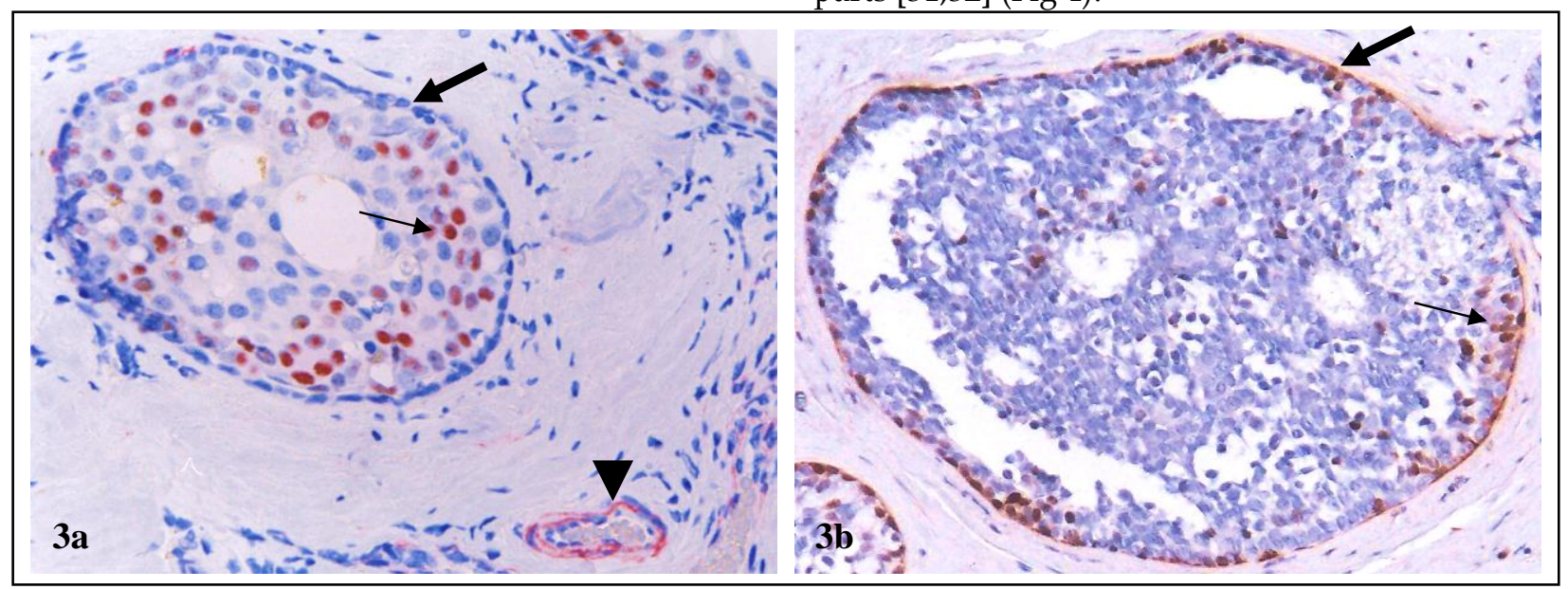

Fig 3. Higher proliferation index in tumors with aberrant expression of tumor suppressors in myoepithelial cell layers. Human breast tumor sections were double immunostained for tumor suppressor WT-I (red) and a cell proliferation marker, Ki-67 (brown). Thick arrows identify myoepithelial cell layers with and without WT-I expression. Thin arrows identify proliferating cells. Arrowhead identifies WT-I positive endothelial cells, which serve as internal controls to indicate that the loss of WT-I staining in the myoepithelial cells is not an artifact. 200X.

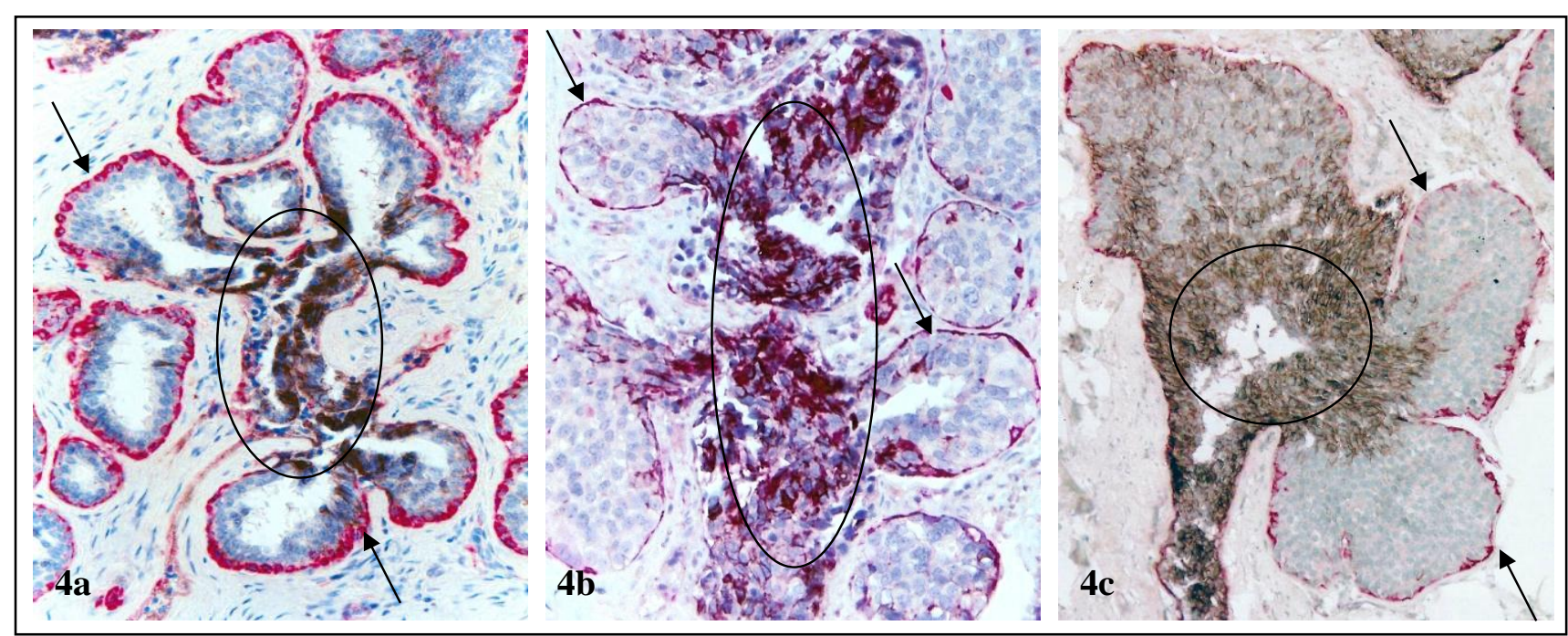

Fig 4. Differential expression of cell surface adhesion molecule E-cadherin in lobular and ductal cells. Human breast tissue sections were double immunostained for SMA (red) and E-cadherin (black). Arrows identify myoepithelial cell layers in normal (a), hyperplastic (b), and pre-invasive (c) lobular lesions. Circles identify E-cadherin positive ductal cells. Note that the lobular cells are devoid of E-cadherin expression, while their associated ductal cells are strongly positive. $150 X$. 
In the lobular system, elevated cell proliferation or malignancy-associated changes are often simultaneously present at the entire lobular structures of morphologically normal appearing lobules, in which all tumor cells share a similar morphological and immunohistochemical profile with adjacent invasive lesions [23,24] (Fig 5a-5d). In contrast, elevated cell proliferation and malignancy-associated changes are only seen at or near focally disrupted myoepithelial cell layers (defined as a gap larger than the combined size of at least 3-myepithelial cells in at least 3 consecutive sections), in which the "budding" tumor cells are morphologically and immunohisto-chemically distinct from their adjacent counterparts within the tumor core [ 25-30] (Fig 5e-5h).

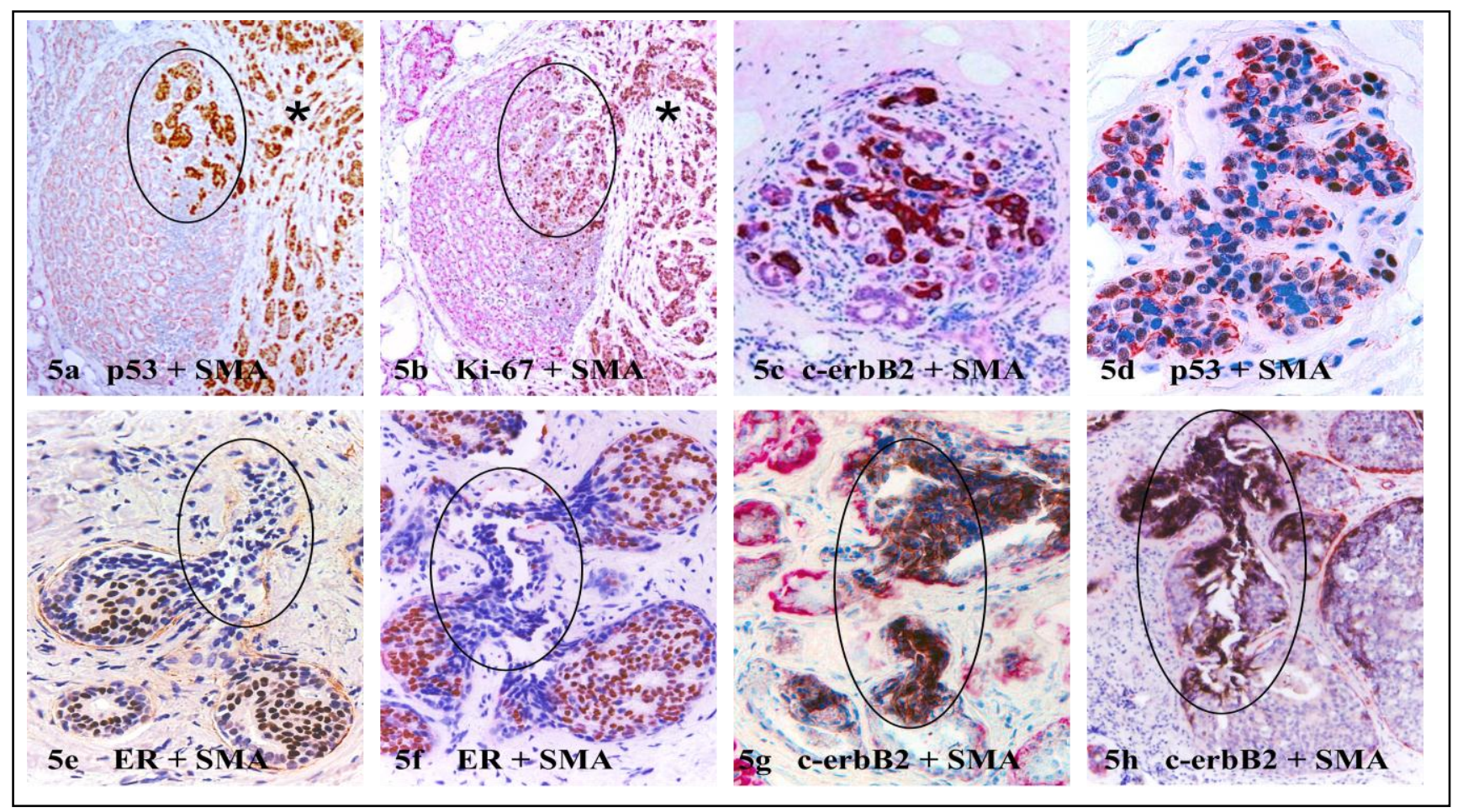

Fig 5. Comparison of the growth pattern and molecular profiles in potential precursors of invasive lesions. Human breast tissue sections were double immunostained for different markers. Circles identify potential precursors of invasive lesions (asterisks). Note that malignancy-associated changes are seen at multiple or the entire lobular elements, while are only present at or near focally disrupted myoepithelial cell layers with different profiles in the ductal system. $200 X$.

Similar alterations and focal disruptions have been detected in the human prostate basal cell layer, which is structurally equivalent to the breast myoepithelial cell layer [33-38]. Similarly, aberrant expression of tumor suppressors and focal disruptions on the basal cell layer have the same impact on the associated prostate tumor cells [33-38].

\section{Our hypothesis}

Based on the above findings and the following facts: [1] the epithelial component of the human breast consists of acinar cells that are mainly for the milk production, and duct cells, which are mainly for providing the drainage for the secretions, [2] lobular buds derive from terminal ducts during breast morphogenesis, and [3] normal, hyperplastic, and in situ neoplastic lobular cells can be distinguished from ductal cells by morphology and expression of E-cadherin, we propose that the structural and functional difference in their surrounding myoepithelial cell layers may represent a trigger factor accounting for the substantial difference in clinical outcomes between ILC and IDC. We define lobular cells as acinar or secretory cells that are mainly for the milk production. Consequently, we refer lobular carcinoma as cancers consisting of malignant acinar or secretory cells.

Alterations in the myoepithelial cell layer may directly impact the clinical outcomes of ILC and IDC by controlling the genetic property and biological behavior of the precursors of invasive lesions, and by dictating the lobular and ductal tumors to follow different pathways for invasion and/or metastasis. More 
specifically, the less consistent expression of tumor suppressors in the myoepithelial cell layer of the lobular system would permit extensive proliferation, differentiation, molecular and biochemical changes at the productive age, especially during pregnancy, which could exhaust or "use up" the residual stem cells. Consistent with this speculation is the fact that a number of case-control studies have consistently shown that long-standing lactation and reproductive parameters could significantly reduce breast cancer risk [39-40].

In addition, as aberrant expression of tumor suppressors with malignancy-associated changes are exclusively seen in some acinar clusters or lobules $[23,24]$, degradation of the myoepithelial cell layers could potentially lead to in situ malignant transformation of the entire tumor cell population within a given lobule to invasive lesions. Therefore, lobular lesions may be at greater risk to develop invasion and metastasis to lymph node. This speculation is consistent with a case control study of 37,692 ductal carcinoma in situ (DCIS) and 4,490 lobular carcinoma in situ (LCIS), which showed that patients with LCIS were 5.3-fold more likely than patients with DCIS to develop invasive lobular lesions [41]. Due to the above reasons, invasive and metastatic lobular lesions may have lower potential to initiate new tumor nests in new sites. Consistent with this speculation is the fact that only the tumor cells expressing stem cell markers could significantly contribute to carcinogenesis and tumor progression, or to significant tumor growth in animal models [42-43].

In sharp contrast, as the epithelial component is normally devoid of blood vessels and lymphatic ducts and totally depends on the stroma for its metabolic needs and even survival, a focal myoepithelial cell layer disruption in a given duct could have a number of consequences, including: (a) a localized loss or reduction of tumor suppressors and the paracrine inhibitory functions, which allow the associated tumor cells to undergo elevated proliferation [44-46], (b) focal alterations in the permeability for oxygen, which selectively triggers the exit of stem or progenitor cells from quiescence [47-48], (c) a localized increase of leukocyte infiltration, which directly export growth factors to the associated epithelial cells through direct physical contact [49-53], (d) the direct epithelial-stromal cell contact, which augments the expression of stromal MMP or represses the normal production and distribution of E-cadherin and other cell adhesion molecules, facilitating epithelial-mesenchymal transition and cell motility [54-56], (e) the direct exposure of the epithelial cells to different cytokines, which stimulate an aberrant expression of c-erbB2, which facilitates vasculogenic mimicry and tumor angiogenesis [57-58], and (f) the direct physical contact between newly formed cell clusters and stromal cells further stimulates the production of tenascin and other invasion-associated molecules that facilitate the stromal tissue remodeling and angiogenesis, providing a favorable micro-environment for epithelial cell proliferation and migration [59-60]. Together, these alterations could selectively favor monoclonal proliferation of the overlying tumor progenitors or a biologically more aggressive cell clone. Thus, the invasive and metastatic cells derive from the duct system may have greater potential to form tumor nests in the new tissue sites, and consequently lead to worse prognosis.

\section{Implications of our hypothesis}

If confirmed, our hypothesis would have a number of clinical implications. First, the application of double immunohistochemistry to identify normal appearing lobular clusters with malignancy-associated alterations (as those shown in Fig 5a-5d), and focal myoepithelial cell layer disruptions with "budding" tumor cells (as those shown in Fig $5 \mathrm{e}-5 \mathrm{~h})$ in clinic biopsies would significantly facilitate early detection of individuals at greater risk to develop invasive cancer or pending invasive lesions. Second, as if two independent mechanisms or pathways are involved for lobular and ductal cancer invasion, the precursors of invasive lesions for these tumors are very likely to differ substantially in their morphological, molecular, and/or biochemical profiles. As shown in Fig 5a-5d, the entire cell population within these morphologically normal appearing lobules may directly progress to invasive lesions after degradation of the associated myoepithelial cell layers. In sharp contrast, only the cell clusters overlying focally disrupted myoepithelial cell layers in the ducts (Fig 5e-5h) may progress to invasive cancers through monoclonal proliferation of the overlying tumor stem cells or a biologically more aggressive cell clone. Consequently, microdissection of these potential precursors of invasive lesions for gene expression profiling may lead to identification of more specific molecules for differentiation and intervention of invasive lobular and ductal cancer. Third, as it has been well documented that invasive cancer cells derived from lobular cancer tend to be more ER $(+)$, PR $(+)$, and HER-2 (-), compared to their stage-matched ductal counterpart [1-5], invasive and metastatic lesions derived from these tumors may have different responses to the same therapeutic regimen. Therefore, the development of more specific reagents or detection methods to differentiate lobular and ductal cells 
and their malignant derivatives may have significant therapeutic value.

\section{Conclusions}

Based on our own and other studies, we propose that the structural and functional difference in their surrounding myoepithelial cell layers may represent a trigger factor accounting for the substantial difference in clinical outcomes between ILC and IDC. Alterations in the myoepithelial cell layer may directly impact the clinical outcomes of ILC and IDC by controlling the genetic property and biological behavior of the precursors of invasive lesions, and by dictating the lobular and ductal tumors to follow different pathways for invasion and/or metastasis.

\section{Acknowledgment}

This study was supported in part by grants DAMD17-01-1-0129, DAMD17-01-1-0130, PC051308 from Congressionally Directed Medical Research Programs, BCTR0706983 from The Susan G. Komen Breast Cancer Foundation, 05AA from AFIP/ARP joint research initiative projects, grant 2008-02 from US Military Cancer Institute and Henry M. Jackson Foundation, and 2006CB910505 from the Ministry of Chinese Science and Technology Department.

The opinions and assertions contained herein represent the personal views of the authors and are not to be construed as official or as representing the views of the Department of the Army or the Department of Defense.

\section{Conflict of Interests}

The authors have declared that no conflict of interest exists.

\section{References}

1. Wasif N, Maggard MA, Ko CY, Giuliano AE. Invasive lobular vs. ductal breast cancer: a stage-matched comparison of outcomes. Ann Surg Oncol. 2010;17(7):1862-1869

2. Arpino G, Bardou VJ, Clark GM, Elledge RM. Infiltrating lobular carcinoma of the breast: tumor characteristics and clinical outcome. Breast Cancer Res 2004;6(3):R149-56

3. Toikkanen S, Pylkkanen L, Joensuu H. Invasive lobular carci-noma of the breast has better short- and long-term survival than invasive ductal carcinoma. $\mathrm{Br} \mathrm{J}$ Cancer 1997;76(9):1234-1240

4. Crivellari D, Molino A. Small tumor size and node-negative HER2-positive breast cancer: a step forward for a better treat-ment? J Clin Oncol. 2010;28(16):e257

5. Foulkes WD, Reis-Filho JS, Narod SA. Tumor size and survival in breast cancer--a reappraisal. Nat Rev Clin Oncol. 2010;7(6):348-353

6. Korkola JE, DeVries S, Fridlyand J, Hwang ES, Estep AL, Chen YY, et al. Differentiation of lobular versus ductal breast carci-nomas by expression microarray analysis. Cancer Res 2003;63(21):7167-7175
7. Lee JH, Park S, Park HS, Park BW. Clinicopathological features of infiltrating lobular carcinomas comparing with infiltrating ductal carcinomas: a case control study. World J Surg Oncol 2010;8:34

8. Christgen M, Bruchhardt H, Hadamitzky C, Rudolph C, Stei-nemann D, Gadzicki D, et al. Comprehensive genetic and functional characterization of IPH-926: a novel CDH1-null tu-mor cell line from human lobular breast cancer. J Pathol 2009;217(5):620-632

9. Tubiana-Hulin M, Stevens D, Lasry S, Guinebretiere JM, Bouita L, Cohen-Solal C, et al. Response to neoadjuvant chemotherapy in lobular and ductal breast carcinomas: a retrospective study on 860 patients from one institution. Ann Oncol 2006;17(8): 1228-1233

10. Bussolati G. Actin-rich (myoepithelial) cells in lobular carci-noma in situ of the breast. Virchows Arch B Cell Pathol Incl Mol Pathol. 1980;32(2):165-176.

11. Bussolati G, Botta G, Gugliotta P. Actin-rich (myoepithelial) cells in ductal carcinoma-in-situ of the breast. Virchows Arch B Cell Pathol Incl Mol Pathol. 1980;34(3):251-259

12. Slade MJ, Coope RC, Gomm JJ, Coombes RC. The human mammary gland basement membrane is integral to the polarity of luminal epithelial cells. Exp Cell Res 1999;247:267-278.

13. Zou Z, Anisowicz A, Hendrix MJ, et al. Maspin, a serpin with tumor-suppressing activity in human mammary epithelial cells. Science 1994;263:526-529

14. Barbareschi M, Pecciarini L, Cangi MG, et al. p63, a p53 homo-logue, is a selective nuclear marker of myoepithelial cells of the human breast. Am J Surg Pathol 2001;25:1954-1960

15. Man YG, Sang QXA. The significance of focal myoepitehlial cell layer disruptions in breast tumor invasion: a paradigm shift from the "protease-centered" hypothesis. Exp Cell Res 2004;301: 103-118

16. Li JH, Man YG. Dual usages of single Wilms' tumor 1 immu-nohistochemistry in evaluation of breast tumors: A preliminary study of 30 cases. Cancer Biomarkers 2009;5(3):109-116

17. Xu ZL, Wang W, Deng CX, Man YG. Aberrant p63 and WT-1 expression in myoepithelial cells of pregnancy-associated breast cancer: implications for tumor aggressiveness and inva-siveness. Int J Biol Sci 2009;5(1): 82-96

18. Hsiao YH, Siddiqui S, Man YG. Dual use of a single Wilms' tumor 1 immunohistochemistry in evaluation of ovarian tu-mors: a preliminary study of 20 cases. J Cancer 2010;1:93-97

19. Zhang R, Man YG, Vang RS, Saenger JS, Barner R, Wheeler D, et al. A subset of morphologically distinct mammary myoepi-thelial cells lacks corresponding immunophenotypic markers. Breast Cancer Res 2003;5: R151-156

20. Hsiao YH, Su YA, Tsai HD, Mason JT, Chou MC, Man YG. Increased invasiveness and aggressiveness in breast epithelia with cytoplasmic p63 expression. Int J Biol Sci 2010;6(5): 428-442

21. Man YG. Focal degeneration of aged or injured myoepithelial cells and the resultant auto-immunoreactions are trigger factors for breast tumor invasion. Medical Hypotheses 2007;69(6):1340-1357

22. Man YG. Bad seeds produce bad crops: a single step-process of breast carcinogenesis and pProgression. Bioscience Hypotheses. 2008;1:147-155

23. Hsiao YH, Deng CX, Mason JT, Chou MC, Man YG. Hidden malignant cells within leukocyte aggregates in normal or hyperplastic tissues of pregnancy-associated breast cancer. Cancer Epid, in press

24. Hsiao YH, Chou MC, Fowler C, Mason JT, Man YG. Breast cancer heterogeneity: mechanisms, proofs, and implications. Journal of Cancer 2010;1: 6-13

25. Yousefi M, Mattu R, Gao C, Man YG. Mammary ducts with and without focal myoepithelial cell layer disruptions show a dif-ferent frequency of white blood cell infiltration and growth 
pattern: Implications for tumor progression and invasion. AIMM 2005;13:30-37

26. Man YG, Tai L, Barner R, Vang R, Saenger JS, Shekitka KM, et al. Cell clusters overlying focally disrupted mammary myoe-pithelial cell layers and adjacent cells within the same duct display different imunohisto-chemical and genetic features: implications for tumor progression and invasion. Breast Cancer Res 2003;5: R231- 241

27. Man YG, Zhang Y, Shen T, Vinh TN, Zeng X, Tauler J, Mulshine JL, Strauss BL. cDNA expression profiling identifies elevated expressions of tumor progression and invasion related genes in cell clusters of in situ breast tumors. Breast Cancer Res Treat 2005;89:199-208

28. Man YG, Zhao CQ, Wang J. Breast tumor cell clusters and their budding derivatives show different immunohistochemical profiles during stromal invasion: implications for hormonal and drug therapies. Cancer Therapy 2006;4: 193-204

29. Man YG, Nieburgs HE. A subset of cell clusters with malignant features in morphologically normal and hyperplastic breast tissues. Cancer Detect Prev 2006;30 (3): 239-247

30. Man YG. Tumor cell budding from focally disrupted tumor capsules: a common pathway for all breast cancer subtype de-rived invasion? Journal of Cancer. 2010;1: 27-31

31. Wahed A, Connelly J, Reese T. E-cadherin expression in pleo-morphic lobular carcinoma: an aid to differentiation from ductal carcinoma. Ann Diagn Pathol. 2002;6(6):349-351

32. Acs G, Lawton TJ, Rebbeck TR, LiVolsi VA, Zhang PJ. Diffe-rential expression of E-cadherin in lobular and ductal neop-lasms of the breast and its biologic and diagnostic implications. Am J Clin Pathol. 2001;115(1): 85- 98

33. Man YG, Shen T, Zhao YG, Sang QX. Focal prostate basal cell layer disruptions and leukocyte infiltration are correlated events: A potential mechanism for basal cell layer disruptions and tumor invasion. Cancer Detect Prev 2005;29: 161-169

34. Man YG, Zhao CQ, Wang J, XL Chen. A subset of prostate basal cells lacks corresponding phenotypic markers. Patholo-gy-Research \& Practice, 2006;202 (9): 651-662

35. Man YG and Gardner WA. Focal degeneration of basal cells and the resultant auto-immunoreactions: a novel mechanism for prostate tumor progression and invasion. Med Hypotheses 2008;70: 387-408

36. Man YG, Gardner WA. Bad seeds produce bad crops: a single step-process of prostate carcinogenesis and Progression. Int J Biol Sci 2008;4: 246-258

37. Liu AJ, Wei LX, Gardner WA, Man YG. Correlated alterations in prostate basal cell layer and basement membrane. Int J Biol Sci 2009;5: 276-285

38. Man YG. A seemingly most effective target for early detection and intervention of prostate tumor invasion. J Cancer 2010;1: 63-69

39. Jordan I, Hebestreit A, Swai B, Krawinkel MB. Breast cancer risk among women with long-standing lactation and reproductive parameters at low risk level: a case-control study in Northern Tanzania. Breast Cancer Res Treat. 2010; [Epub ahead of print].

40. Russo J, Balogh GA, Russo IH. Full-term pregnancy induces a specific genomic signature in the human breast. Cancer Epi-demiol Biomarkers Prev. 2008;17(1): 51-66

41. Li CI, Malone KE, Saltzman BS, Daling JR. Risk of invasive breast carcinoma among women diagnosed with ductal carci-noma in situ and lobular carcinoma in situ, 1988-2001. Cancer. 2006;106(10): 2104-2112

42. Honeth G, Bendahl PO, Ringner M, Saal LH, Gruvberger-Saal SK, Lovgren K, et al. The CD44+/CD24- phenotype in enriched in basal-like breast tumors. Breast Cancer Res. 2008;10(3):R53
43. Guest I, IIic Z, Grant D, Glinsky G, Sell S. Direct and indirect contribution of bone marrow-derived cells to cancer. Int J Cancer. 2010;126(10): 2308-2318

44. Brummer T, Schramek D, Hayes VM, et al. Increased prolifera-tion and altered growth factor dependence of human mammary epithelial cells overexpressing the Gab2 docking protein. J Biol Chem. 2006;281:626-631

45. Oliveira AM, Ross JS, Fletcher JA. Tumor suppressor genes in breast cancer: the gatekeepers and the caretakers. Am J Clin Pathol. 2005;124(Suppl):S16-28

46. Yanochko GM, Eckhart W. Type 1 insulin-like growth factor overexpression induce proliferation and anti- apoptotic sig-naling in a three-dimensional culture model of breast epithelial cells. Breast Cancer Res. 2006;8(2): R18-R23

47. Chakravarthy MV, Spangenhurg EE, Booth FW. Culture in low levels of oxygen enhances in vitro proliferation potential of satellite cells from old skeletal muscles. Cell Mol Life Sci. 2001;58: 1150-1158

48. Studer L, Csete M, Lee SH. Enhanced proliferation, survival, and dopaminergic differentiation of CNS precursors in lowed oxygen. J Neurosci 2000; 20: 7377-83.

49. Asano-kato N, Fukagawa K, Okada N. Tryptase increase proli-ferative activity of human conjunctive fibroblasts through protease-activated receptor. Invest Ophthalmol Vis Sci. 2005;46: $4622-4626$

50. Freeman MR, Schneck FX, Gognon ML, et al. Peripheral blood T-lymphocytes and lymphocytes infiltrating human cancers express vascular endothelianl growth factor: a potential role for T cells in angiogenesis. Cancer Res. 1995;55: 4140-4145

51. Nienartowicz A, Sobaniee-Lotowska ME, et al. Mast cells in neoangiogenesis. Med Sci Monit. 2006;12(3): 53- 56

52. Qu Z. Immunohistological detection of growth factors and cytokines in tissue mast cells. Methods Mol Biol 2006;315:257-272

53. Takahashi Y, Bucana CD, Liu W, et al. Platelet-derived endo-thelial cell growth factor in human colon cancer angiogenesis: role of infiltrating cells. J Natl Cancer Inst. 1996;88: 1146-1151

54. Kang Y, Massague J. Epithelial-mesenchymal transition: twist in development and metastasis. Cell. 2004;118: 277-279

55. Sato T, Sakai T, Noguchi Y, Takita M, Hirakawa S, Ito A. Tu-mor-stromal cell contact promotes invasion of human uterine cervical carcinoma cells by augmenting the expression and ac-tivation of stromal matrix metalloproteinases. Gynecol Oncol. 2004;92: 47-56

56. Strizzi L, Bianco C, Normanno N. Epithelial mesenchymal transition is a characteristic of hyperplasias and tumors in mammary gland from MMTV-Criptol-1 transgenic mice. J Cell Physiol. 2004;201:266-276

57. Klos KS, Wyszomierski SL, Sun M et al. c-erbB2 increases vas-cular endothelial growth factor protein synthesis via activation of mammalian target of rapamycin/p70S6K leading to in-creased angiogenesis and spontaneous metastasis of human breast cancer cells. Cancer Res. 2006;6(4):2028-2037

58. Carter WB, Hoying JB, Boswell C, Williams SK. HER2/neu over-expression induces endothelial cell retraction. Int J Cancer. 2001;91(3):295-299

59. Verstraeten AA, Mackie EJ, Hageman PC, et al. Tenascin ex-pression in basal cell carcinoma. Brit J Dermt. 1992;127: 571-574

60. Ilunga $\mathrm{K}$, Nishiura $\mathrm{R}$, Inada $\mathrm{H}$, et al. Co-stimulation of human breast cancer cells with transforming growth factor-beta and tenasicin-c enhances matrix metalloproteinase- 9 expression and cancer cell invasion. Int J Exp Pathol. 2004;85: 373-379 